\title{
RAZVOJ INTERKULTURNE KOMPETENCIJE I PRIMENA STANDARDA ZA KRAJ OSNOVNOG OBRAZOVANJA: SMERNICE ZA NASTAVU ITALIJANSKOG JEZIKA
}

\begin{abstract}
U obrazovnom sistemu Republike Srbije interkulturna kompetencija predstavlja jednu od ključnih kompetencija koju učenik treba da razvije na kraju ciklusa osnovnog obrazovanja u okviru nastave stranog jezika i shodno tome ima važno mesto u Opštim standardima postignuća za kraj osnovnog obrazovanja za strane jezike ${ }^{1}$. Razvoj interkulturne svesti i pismenosti kod pojedinca važan je za njegovo bolje integrisanje u današnje društvo. Ipak, interkulturni pristup je i dalje novost u nastavnom procesu i neretko se dešava da kulturološki sadržaji ne bivaju obrađeni tokom godine usled smanjenog fonda časova stranih jezika u školama ili usled problema evaluacije stečene interkulturne kompetencije. Sa druge strane, standardi su neretko shvaćeni kao ograničenje kreativnosti tokom nastave i dodatni pritisak nastavnicima tokom izrade mesečnih i godišnjih planova. Stoga je cilj ovog rada da ukaže na važnost interkulturnih elemenata u obrazovanju i da olakša primenu interkulturnih metoda na časovima. Nakon osvrta na razvoj interkulturnog pristupa u glotodidaktici i pregleda osnovnih postulata na kojima počivaju Standardi, ponudićemo preporuke za nastavnu praksu italijanskog kao drugog stranog jezika u osnovnim školama, odnosno smernice i ideje za konkretnu obradu nastavnih sadržaja sa ciljem pomoći nastavnicima u odabiru zadataka za razvoj interkulturne svesti kod učenika.
\end{abstract}

Ključne reči: interkultura, kultura, strani jezici, glotodidaktika, interkulturna kompetencija, standardi

\section{Uvod}

U ovom radu ćemo objasniti pojam interkulture i njenu povezanost sa obrazovanjem, sa posebnim akcentom na razvoj interkulturne kompetencije u nastavi stranih jezika u osnovnoj školi. Pregledom ključnih defi-

\footnotetext{
* tijana.gsh@gmail.com

$1 \quad$ U daljem tekstu: Standardi
} 
nicija Uneska i Evropske komisije, upoznaćemo se sa važnošću interkuturne svesti u multikulturnom društvu današnjice radi uspostavljanja i održanja ravnopravnog odnosa među kulturama. Objasnićemo šta podrazumeva interkulturni pristup u učenju stranih jezika i kako je nastalo drugačije poimanje sprege između jezika i kulture. Interkulturna komunikativna kompetencija se sastoji iz više komponenti, koje se u nastavnom procesu mogu sinhronizovano usvajati putem odgovarajućih metoda i postupaka didaktizacije kulturoloških sadržaja iz udžbenika i dodatnih materijala. Standardi su zvanično utvrđeni Pravilnikom 2017. godine (,Službeni glasnik RS", br. 88/2017 od 29.9.2017), a Priručnik za nastavnike dostupan je u vidu dokumenta na sajtu ZVKV-a. ${ }^{2}$ Formalnim i sadržinskim pregledom Standarda i Priručnika za nastavnike uvidećemo njihov značaj za uspešan i kvalitetan obrazovni proces, a na samom kraju ćemo ponuditi predloge i zadatke za razvoj i evaluaciju interkulturne komunikativne kompetencije za italijanski kao strani jezik.

\section{Interkultura i obrazovanje}

Budući da je karakter našeg društva multikulturalan, promišljanje o sopstvenoj kulturi neretko priziva u svest i druge kulture, radi poređenja po sličnosti i razlikama ili boljeg objašnjenja pojedinih fenomena. Kulturna raznolikost predstavlja mnogostruke načine na koje kulture grupa i društava nalaze svoj izraz i može se izjednačiti sa manifestacijom raznovrsnosti života na zemlji (Unesco, 2003: 11). Sam termin „multikulturno“ odnosi se na heterogenu prirodu ljudskog društva, a „multikulturnost“" na činjenicu da ljudi drugačijih kultura žive jedni pored drugih. Budući da je cilj obrazovanja unapređivanje demokratije u zajednici, svrha obrazovnog sistema predstavlja uspostavljanje i održanje miroljubivog zajedničkog života i razvijanje pozitivnih osećanja među različitim kulturnim grupama (Most, 2007: 5). Koncept „interkulturnog“ je dinamičniji i odnosi se na razvijanje odnosa između ljudi koji pripadaju različitim kulturama, a pojam „,interkulturnosti“ prevazilazi puki multikulturan suživot i označava interakciju kultura, uz međusobnu zainteresovanost, prihvatanje i poštovanje. Interkulturnost ukazuje i na razmenu među kulturama i dijalog na lokalnom, regionalnom, nacionalnom i internacionalnom nivou (Most, 2007: 
6). Interkulturna komunikacija se razvija radi ravnopravnog, tolerantnog i otvorenog odnosa među nacionalnim kulturama, što su centralni principi Uneska (Tomić, 2009: 494).

Usled društvenih prilika u modernom i savremenom dobu, pojedine humanističke nauke su sa svojih aspekata počele da se bave pojmom interkulturnosti. Sa ciljem uspostavljanja i olakšanja međukulturnog dijaloga, različite discipline se ,bave problemom uspostavljanja komunikacije među pripadnicima različitih tradicija i proučavaju kulturne obrasce, jezičke simbole, verovanja, stavove, vrednosti, očekivanja, norme i načine ponašanja, strategije komuniciranja, sticanje znanja i veština koje smanjuju međukulturno nerazumevanje i antagonizam“ (Mimica \& Bogdanović, 2007: 198-199. prema Durbaba, 2016: 50). Usled globalizacije, u sociologiji se pojavljuje potreba za interkulturnim obukama koje imaju za cilj da olakšaju interkulturno razumevanje. U antopologiji i etnologiji razvijaju se pojmovi etnocentrizma i kulturnog relativizma. Etnocentrizam podrazumeva posmatranje tuđih kultura sa stanovišta sopstvene i svoje otelotvorenje nalazi u kritikama i netrpeljivosti, a u krajnjoj istanci u šovinizmu i rasizmu. Kulturni relativizam, pak, pretpostavlja prihvatanje različitih kultura i svest o različitim vrednosnim sistemima (Durbaba, 2006: 52-59). S tim u vezi, valja pomenuti i takozvani Benetov (Milton Bennett) model razvoja interkulturne osetljivosti koji ima za cilj prihvatanje kulturnih razlika i koji pretpostavlja razvoj od krajnjeg etnocentrizma ka potpunom etnorelativizmu. Lingvistika i glotodidaktika se takođe bave interkulturom, budući da su jezik i kultura u neraskidivoj vezi. Interkulturno orijentisana lingvistika izučava uticaj kulture na jezičke pojave, nadasve na polju semantike i pragmatike, dok je glotodidaktika integrisala usvajanje kulturnih znanja i interkulturnu kompetenciju u koncept komunikativne nastave (Durbaba, 2016: 60-61).

Jasni ciljevi interkulturnog učenja mogu se objasniti četirma stubovima obrazovanja koje preporučuje Međunarodna komisija o obrazovanju za XXI vek: učiti da znam, učiti da uradim, učiti da živim zajedno sa drugima i učiti da budem (Delors, 1996: 86-97). Dok se prvi odnosi na uspešno kombinovanje opštih znanja u konkretnom radu, drugi pretpostavlja sticanje kompetencija širih od samog poznavanja posla, kako bi se učenici snalazili u različitim situacijama i uspešno funkcionisali u timu. Treći stub odnosi se na razvijanje razumevanja za druge ljude i uvažava- 
nje uzajamne zavisnosti poštujući vrednosti pluralizma, mira i kulturne različitosti. Poslednji stub podrazumeva lični razvoj sa ciljem poboljšanja samostalnosti, prosuđivanja i lične odgovornosti, na način koji podržava lični kulturni potencijal zasnovan na pravu na različitost. Iz priloženog se jasno vidi da interkulturno obrazovanje ima za cilj da pruži znanja, veštine i vrednosti kojima pojedinac, putem upoznavanja drugih kultura, razvija duh solidarnosti i saradnje, ali i otkriva vlastitu kulturu (EPALE, 2017).

\section{Interkulturni pristup u nastavi stranih jezika}

Evropska komisija objavila je 1995. dokument pod nazivom Teaching and learning: towards the Learning Society ili skraćeno White paper, koji u svetlu novih prilika na globalnom nivou nudi smernice i strategije za obrazovanje i obuke sa ciljem uspešnijeg nalaženja posla i poboljšanja socijalne kohezije. Jedan od glavnih principa kojim se ovaj dokument vodi je celoživotno učenje. Na samom početku ističe se važnost učenja stranih jezika zarad uspešnog plasiranja na globalno tržište rada. Evropska komisija smatra da je neophodno dobro poznavanje još bar dva druga jezika pored maternjeg za svakog građanina Evrope, kao i da je učenje stranih jezika uopšte važno kako bi se otvorio um, stimulisala intelektualna agilnost i proširili kulturni horizonti (European Commission, 1995: 13). Da bi se uspešno došlo do tog cilja, preporučeno je rano učenje stranih jezika u predškolskim ustanovama. Predlaže se postepeno uvođenje stranih jezika (jedan u nižim razredima osnovne škole, a drugi u višim), kao i slušanje određenih školskih predmeta na prvom stranom jeziku (European Commission, 1995: 47). Aktuelni evropski stavovi zastupaju načelo višejezičnosti u obrazovanju kao garant ravnopravnosti i jedinstva.

Konferencija u Daremu, koju su 1986. organizovali Majkl Bajram (Michael Byram) i Diter Butjes (Dieter Buttjes), može se smatrati ključnom tačkom u uspostavljanju interkulturno orijentisane nastave (Durbaba, 2016: 257). U Predgovoru zbornika radova sa konferencije, koji je objavljen 1991. godine, autori ističu da su na skupu pokušali da dodaju međunarodnu perspektivu u pitanje učenja stranih jezika. Cilj konferencije se ogleda u oživljavanju interesovanja za kulturne sadržaje i za političko-obrazovnu svrhu nastave stranih jezika. Na taj način, poznavanje stranog jezika ne omogućava samo komunikaciju među društvima, već razvija komponente 
socijalne korisnosti i obogaćivanja života pojedinca nezavisno od njegove društvene i nacionalne pripadnosti. Autori ističu da integrisanim učenjem jezika i kulture nastava neće stvoriti učenike sa konzumističko-turističkom kompetencijom, koja pruža ograničene mogućnosti prilikom kontakta sa ciljnom kulturom, nego učenike koji su prešli kritički prag i u stanju su da uspešno snalaze u stranoj zemlji. Cilj razvijanja interkulturne kompetencije ogleda se u prevazilaženju monokulturnog nivoa svesti i etnocentričnosti i otvaranju uma za nove poglede na svet (Buttjes \& Byram, 1991: 3-8).

Homi Baba (Homi K. Bhabha) razvija koncept trećeg mesta, odnosno prostora u kojem je moguće sagledati elemente iz dveju različitih kultura i prisvojiti nova značenja. Na tragu pomenute teorije, Majkl Bajram (Michael Byram) i Kler Kramš (Claire Kramsch) definisali su sledeće postupke didaktizacije kulturoloških sadržaja u interkulturnoj nastavi:

1. analiza određene pojave ili komunikacione situacije najpre u sopstvenom (The First Place) a potom i u stranom kulturnom habitusu (The Second Place);

2. poređenje u cilju iznalaženja poklapanja i razilaženja, sličnosti i razlika;

3. promišljanje o mogućim načinima reagovanja na datu pojavu ili situaciju, pomeranjem sa dotadašnje tačke gledišta, promenom perspektive i izlaskom u međuprostor (The Third Place) i izborom interkulturno osetljivog načina komunikacije (Kramsch, 1993; Byram, 1997. prema Durbaba, 2016: 78).

Nakon rada na kreiranju smernica i sadržaja za interkulturnu glotodidaktiku, Bajram razvija svoj poznati model interkulturne kompetencije. Njeni segmenti nalaze se u mnogim aktuelnim kurikulumima za učenje stranih jezika. On je, naime, razložio interkulturnu kompetenciju na pet složenih kategorija znanja (fr. savoirs):

- znanja (franc. savoirs), koja se odnose na „poznavanje verovanja, ponašanja i kulturnih značenja koje dele različite društvene grupe jedne zemlje, kao i na poznavanje interpersonalne interakcije na ličnom i društvenom nivou";

- stavovi (franc. savoir être), koji se zasnivaju na ,analizi verovanja, vrednosti i ponašanja drugih kultura i relativizaciju sopstvenih"; 
podrazumevaju pokazivanje znatiželje, otvorenost i spremnost na susret sa nepoznatim;

- veštine interpretiranja (franc. savoir comprendre), koje predstavljaju sposobnost i veštinu da se razume i interpretira događaj ili situacija iz druge kulture i poveže sa odgovarajućim elementima sopstvene kulture. Podrazumevaju ,pronalaženje zajedničkih tačaka ili kontradikcija koje se mogu rešiti, identifikaciju stereotipa i uzroka nesporazuma";

- veštine otkrivanja i interakcije (franc. savoir apprendre/faire), koje se vezuju za veštinu da se bude u interakciji sa drugom kulturom i sposobnost da se usvajaju znanja i iskustva koja joj pripadaju. Da bi se usvojilo novo znanje, važno je ,,prepoznati značajne kulturne fenomene, dati im smisao i dovesti uh u vezu sa drugim fenomenima“;

- kritička kulturna svest (franc. savoir s'engager), koja predstavlja sposobnost da se kritički promišlja i procenjuje iz različitih perspektiva, te $i$ da se određeni sadržaj na odgovarajući način produkuje kako unutar maternje tako i unutar ciljne kulture (Byram 1997: 34 prema Andrijević, 2016: 118-119. i Durbaba, 2016: 288).

U radu Developing the Intercultural Dimension in Lanuage Teaching. A Practical Introduction for Teachers, autori bliže određuju koja tačno znanja, stavovi i vrednosti čine nastavni proces. Da bi se usvojio pozitivan stav i otvorenost prema drugim kulturama (savoir être), u procesu učenja neophodno je relativizovati već usvojene vrednosti, verovanja i ponašanja sa pretpostavkom da nisu jedina moguća i prirodna. Znanja (savoirs) koja se razvijaju tiču se polaznih i ciljnih društvenih grupa i procesa njihovog rada i prakse. Budući da je nemoguće predvideti koja konkretna znanja će biti korisna učenicima prilikom interkulturnog kontakta, nastavnici treba da se koncentrišu na razvijanje veštine medijacije, tačnije sposobnosti poređenja, tumačenja i povezivanja (savoir comprendre). Na primer, kako da protumače dokument ili događaj iz druge kulture i da povežu sa sličnom pojavom u polaznoj kulturi. Naime, važno je usmeriti učenike na veštine otkrivanja i interakcije (savoir apprendre/faire), to jest, naučiti ih kako da usvajaju nova znanja o kulturi i običajima i da koriste stečena znanja u konkretnoj komunikaciji. Na kraju procesa učenja, medijatori treba da ra- 
zviju i kritičku kulturnu svest (savoir s'engager), veštinu neophodnu kako bi se zaista razumeo duboko ukorenjeni sistem verovanja koji je kreirala polazna kultura i da bi se moglo pristupati određenim pojava iz različitih perspektiva. Naime, cilj učenja nije promena vrednosnog sistema učenika, već njegovo osvešćivanje i racionalizovanje (Byram, Gribkova i dr., 2002: 11-13). Takođe, budući da je postojanje stereotipa u svetu i pojedincu neminovno, bili oni pozitivni ili negativni, interkulturna glotodidaktika ima za cilj njihovo osvešćivanje kod učenika i prevazilaženje površnih odnosa koji su rezultat stereotipnih predstava, kao što je Savet Evrope definisao u Zajedničkom evropskom okviru za izučavanje, nastavu i ocjenjivanje jezi$k a^{3}$ u poglavlju 5.1.2.2 (2003: 110).

Kao što savetuje i savremena didaktika, interkulturni pristup učenju stranih jezika podržava korišćenje autentičnih materijala (tekstova, audio i video zapisa, pisanih i crtanih dokumenata) uz aktivnosti koje razvijaju razumevanje i diskusiju. Prilikom didaktizacije takvih materijala valja podsticati učenike da razmenjuju različite stavove i poglede. Važno je koncentrisati se na analizu samog teksta, a ne na faktografske informacije, kako bi učenici razumeli kontekst i spoznali drugačiju perspektivu u obradi tema koji su im potencijalno već poznate iz polazne kulture (Byram, Gribkova i dr., 2002: 23-24).

Jedan od glavnih problema koji prati integrisanje interkulturne komunikativne kompetencije u nastavi je evaluacija. Dok je veoma lako oceniti učenikovo znanje o informacijama i činjenicama putem testova, uopšte nije jednostavno odrediti kako bi trebalo da izgleda test provere stečene interkulturne kompetencije. Ipak, može se koristiti ocenjivanje nečijeg znanja i razumevanja esejskim pitanjima, kao što je to slučaj sa proučavanjem književnosti. To su, naime, samo dva dela interkulturne komunikativne kompetencije (savoir i savoir comprendre). Najteže je proceniti da li su učenici zaista obogatili svoj stav višim stepenom tolerancije prema različitosti. Jedan od načina prevazilaženja tradicionalnog ocenjivanja, koji u ovom slučaju može biti od pomoći, jeste vođenje evidencije o stečenim kompetencijama (Byram, Gribkova i dr., 2002: 29-32). Savet Evrope je kao rešenje ponudio Evropski jezički portfolio sa namerom da podrži višejezičnu obrazovnu politiku, kontinuirano učenje jezika tokom života, 
razvijanje samostalnosti u učenju i povećavanje koherentnosti i transparentnosti jezičkih programa. Svaki portfolio sastoji se iz takozvanog pasoša (skale za autoevaluaciju nivoa za svaku jezičku kompetenciju i svaki jezik koji se zna), jezičke biografije (učenik navodi svoje jezičke i kulturne kompetencije) i dosijea (učenik sakuplja sve što dokazuje kompetencije, to jest, svoje radove, sertifikate i diplome; Tagliante, 2009: 76). Fred Dervin (Fred Dervin) smatra da veštine prepoznavanja, analize i poređenja kulturoloških činjenica mogu biti predmet brojčanog i opisnog ocenjivanja, ali na višim nivoima učenja jezika $\mathrm{i}$ to $\mathrm{u}$ kontekstima univerziteta, prakse $\mathrm{i}$ studentske mobilnosti (Dervin, 2010: 10). S obzirom na to da portofolio i autobiografije ostaju isključivo lični dokumenti učenika, nedostatak boljeg rešenja problema evaluacije oduzima legitimnost ciljevima interkulturnog pristupa (Beacco, Byram i dr., 2016: 70).

\section{Opšti standardi postignuća za kraj osnovnog obrazovanja za strani jezik}

Standarde i Priručnik za nastavnike je sastavila radna grupa eksperata na polju glotodidaktike i metodike na osnovu ,analize relevantnih dokumenata, empirijskih podataka $i$ iskustava iz nastavne prakse $i$ ispitivanja stavova nastavnika o prvobitnom predlogu Stantarda“". U uvodnom delu Priručnika se kao cilj navodi unapređenje kvaliteta obrazovanja, a dokument je sastavljen tako da pomogne nastavnicima u korišćenju standarda u radu. Stoga su kompetencije definisane i pomoću ilustrativnih zadataka, koji mogu biti modelom za kreiranje konkretnih aktivnosti prilikom nastavnog procesa (Đurić, Durbaba i dr., 2017: 4).

U poglavlju „Višejezičnost kao suštinska obrazovna vrednost“, primećujemo postulate Evropske komisije i Saveta Evrope - višejezičnost kao cilj evropskog obrazovanja, odstupanje od monokulturnog obrazovnog okruženja, plasiranje na tržište rada, postepeno uvođenje stranih jezika u školama, osnovi za celoživotno učenje i slično. U sledećem poglavlju govori se o sticanju komunikativne kompetencije kao opštem cilju učenja stranih jezika. Naime, pored kognitivnih i afektivnih aspekata ličnosti, učenje stranih jezika potpomaže i razvoj opštih kompetencija, prevashodno socijalnih i komunukacionih. Ističe se značaj povezanosti nastave stranih jezika sa ostalim nastavnim predmetima sa ciljem razvoja međupred- 
metne kompetencije, ponajviše u slučaju delimične ili potpune dvojezične nastave (CLIL). Takođe, autori ukazuju na potencijalne probleme u nastavi uslovljene malim fondom časova ili nedovoljnom broju učenika u odeljenju, a kao rešenje se predlaže kompenzacija putem inovativnih metoda savremene didaktike kao što su korišćenje medija, projektni, kooperativni i tandemski rad, kao i razvijanje strategija i inspiracije za autonomni rad u usavršavanju stranog jezika. U poglavlju „Povezanost nastavnih programa, ishoda učenja i obrazovnih standarda" nude se programi, ishodi i standardi kao okvir za osmišljavanje nastavnog proseca koji nije isključivo baziran na korišćenju udžbenika. Naime, iz programa (opis sadržaja i aktivnosti) proizilaze ishodi (ostvareni ciljevi učenja) iz kojih potom proizilaze standardi čiji je cilj da olakšaju proveru rezultata i kvaliteta naučenog. U Priručniku za standarde nalaze se zadaci koji ilsutruju primenu određenih standarda u vidu predloga aktivnosti kojima su postignuća merljiva, u skladu sa ZEO. Takođe, njihova je uloga „dobrog sluge“, te ne predstavaju konačan pregled naučenog, već sredstvo za utvrđivanje postignuća koje ima za cilj ujednačeno i transparentno ocenjivanje među svim institucijama školskog sistema (Đurić, Durbaba i dr., 2017: 4-7).

U narednom poglavlju definišu se tri nivoa kompetencija - osnovni, srednji i napredni. Naime, očekuje se da $80 \%$ učenika osnovne škole stekne osnovni nivo, 50\% srednji, a 25\% đaka napredni nivo. Budući da se prvi strani jezik uči duže i ranije se kreće sa njegovim usvajanjem, kompetencije srednjeg nivoa drugog stranog jezika odgovaraju osnovnom nivou prvog, a kompetencije višeg nivoa drugog stranog jezika srednjem nivou prvog. U poglavlju „Forma i elemenetni obrazovnih standarda“ autori nas upoznaju sa formom dokumenta, koji je sačinjen od narativnih opisa kompetencija - svega onoga što učenik treba da zna i ume na određenom stranom jeziku. Kompetencije su definisane na različitim nivoima opštosti, počev od globalne ka specifičnim predmetnim kompetencijama. Standardi obuhvataju ukupno 116 deskriptora za prvi i 114 deskriptora za drugi strani jezik. Potom sledi poglavlje koje opisuje strukturu ponuđenih zadataka, nudi načine njihove konkretne primene i pruža pomoć prilikom njihove evaluacije, uz podršku da se usvoji svako potencijalno tačno rešenje i da se na nižim nivoima ne sankcionišu greške koje ne remete razumljivost iskaza. U poslednjem poglavlju uvoda definišu se specifične predmetne kompetencije u nastavi stranih jezika: razumevanja govora, razumevanja 
pisanog teksta, pisanog izražavanja, usmenog izražavanja, medijacije, lingvistička i interkulturna kompetencija (Đurić, Durbaba i dr., 2017: 8-10).

\section{Interkulturna kompetencija u Standardima i predlozi za nastavnu praksu za italijanski jezik}

Standardi ukazuju na neophodnost sticanja interkulturne kompetencije u svetlu valorizacije učenja društvenih specifičnosti ciljnih kultura i osposobljavanja za poređenje polazne i ciljne kulture bez prisustva stereotipa. Kulturni sadržaji obuhvataju i najviše proizvode civilizacije, ali i osnovne pojave svakodnevnice ciljnih kultura. Ponuđeni zadaci iz dela za interkulurnu kompetenciju mogu poslužiti i ,za proveru pragmatičkih veština, kulturne osetljivosti stavova, verbalnog i neverbalnog ponašanja“ (Đurić, Durbaba i dr., 2017: 13). U ovom poglavlju ćemo se osvrnuti na određene iskaze standarda i pružiti smernice za didaktizaciju u praksi na primerima aktivnosti za njihovu realizaciju u nastavi italijanskog jezika.

Iz opisnih definicija nivoa stečene interkulturne kao specifične predmetne kompetencije jasno je da učenik na osnovnom nivou poznaje opšte pojave u svakodnevnici ciljne kulture, njene ključne geografske i vremenske odrednice, najvažnije ličnosti i pokazuje interesovanje za ciljnu kulturu (vidi tabelu I u Prilogu). Poznavanje osnovnih pojava iz svakodnevnog života može se proveriti aktivnostima povezivanja praznika sa odgovarajućim datumima, kao što je prikazano u zadatku koji odgovara iskazu 1.3.1 u tabeli I u Prilogu na kraju rada. S obzirom na to da udžbenici za strane jezike najčešće pružaju slične osnovne informacije već u uvodnim lekcijama, oni mogu poslužiti nastavniku kao početni stimulans u radu sa učenicima. Ipak, uvek je poželjno da nastavnik donese u razred autentične dodatne materijale kao što su isečci iz novina, reklamni materijal, mape, recepti, audio i video snimci i slično. Fokus na osnovne sadržaje interkultunih aktivnosti može se napraviti, na primer, gledanjem slika ili kratkih video materijala o poznatim ličnostima i velikim gradovima, pravljenjem interaktivnih mapa regija i država ciljnih kultura ili hronoloških linija najvažnijih događaja, projektnim radovima o poznatim jelima ciljne kulture i slično. Učenik može napraviti ili popuniti vremensku liniju ključnih istorijskih događaja u ciljnoj kulturi, kao na primeru zadatka nakon iskaza 1.3.3. u tabeli I u Prilogu. 
Na srednjem nivou učenik treba da prepozna i prokomentariše sličnosti i razlike u svakodnevnici, lepom ponašanju, stereotipima, ekosistemima i slično između polazne i ciljne kulture (vidi tabelu II u Prilogu). Da bi se interkulturna kompetencija razvila na srednjem nivou, nepohodno je skretati pažnju na sličnosti i razlike podesnim pitanjima i poređenjima prikom obrade nastavnih sadržaja, posebno u kulturnim dodacima koji se u udžbenicima često nalaze na kraju lekcije. To se takođe može postići projektnim radovima ili samostalnim radom uz dobro definisane smernice sa nastavnikove strane. Na primerima zadataka nakon iskaza 2.3.1. u tabeli II u Prilogu učenik može povezati svoje znanje o različim datumima proslave Božića u Italiji i Srbiji sa usvojenim znanjima iz istorije o razlici između julijanskog i gregorijanskog kalendara. Kako bi učenik mogao samostalno i uspešno uraditi ovakav tip zadatka, važno je da tokom obrazovnog procesa nastavnici stranih jezika i drugih predmeta primenjuju strategije za razvijanje međupredmetne kompetencije.

Na naprednom nivou, učenik produbljuje znanja sa srednjeg nivoa i razume uticaj prirodnih i društvenih okolnosti na kulturu, prihvata međukulturne razlike i pokazuje otvoren stav i radoznalost prema ciljnim kulturama (vidi tabelu III u Prilogu). Naime, da bi se rešio primer zadatka nakon iskaza 3.3.4. u tabeli III u Prilogu, nije dovoljno da nastavnik samo napomene da Italija ima izlaz na pet mora, već se očekuje da tokom nastave potakne učenike na razmišljanje kako blizina mora utiče na navike u planiranju slobodnog vremena kod Italijana uz stalno poređenje sa polaznom kulturom. Od učenika se ne očekuje da do detalja razume sve pojave i procese tipične za ciljnu kulturu, pošto je interkulturna, kao i većina drugih kompetencija, produkt celoživotnog rada i konstantnog učenja. Ono što je pak važno na sva tri nivoa jeste da učenik usvoji znanja i umenja iz osnovnih i opštih kulturnih kategorija, ali da razvija dodatna znanja u ciljnoj kulturi u skladu sa ličnim interesovanjima, što dokazuju i iskazi tipa: „,2.3.8. Predstavlja i ukratko opisuje na ciljnom jeziku nekoliko poznatih ličnosti i pojava iz ciljnih kultura, kao i one za koje pokazuje interesovanje“" (vidi tabelu II u Prilogu).

Budući da su učenici u osnovnim školama na početku učenja stranog jezika, od njih se ne očekuje da se odmah uhvate u koštac sa analizom najviših ostvarenja ciljne kulture, koja svakako treba da poznaju na osnovnom nivou. Naime, prilikom prvih kontakata sa stranim jezikom, 
važno je da razvijaju svest o autostereotipima i heterostereotipima, kao što navodi Bajram u svom modelu (1994: 50). Na primer, neophodno je govoriti o najčešćim vrstama pica koje se pripremaju i naručuju, o tome kako se priprema kafa ili pasta, kad i kako se konzumira i slično, poredeći sa prisustvom i odsustvom pojava i navika u našoj kulturi. Ipak, uz to valja napomenuti da postoji i drugačija vrsta ishrane koja je prisutna u ciljnoj ili polaznoj kulturi, na primer, razgovarati o vegeterijancima i veganima, pronaći aktuelne statistike vezane za drugačije navike u ishrani, prokomentarisati hrono ishranu i slično.

Smatramo da bi metoda koju su predložili Bajram i Kramš mogla biti veoma korisna za analizu kulturoloških sadržaja u udžbenicima ili dodatnim materijalima. S tim u vezi, predlažemo da se počne sa zasebnom analizom određene pojave u polaznoj i ciljnoj kulturi, potom pređe na traženje sličnosti i razlika, a na kraju prokomentariše koje bi bilo prihvatljivo ponašanje u određenoj situaciji i kulturnom okruženju. Na primer, ukoliko se ukaže prilika da se na času razgovara o muzejima (ili su učenici nedavno posetili neku izložbu), može početi od muzeja koji postoje u njihovom gradu i o istim u nekom italijanskom gradu. Na internetu možemo sakupiti informacije o cenama ulaznica, radnom vremenu muzeja i onome što se može videti u njemu. Možemo prokomentarisati činjenicu da je ulaz u muzeje u Italiji besplatan svake prve nedelje u mesecu (eventualno izvršiti pretragu preko haštaga na instagramu ili tviteru \#domenicaalmuseo), kao i da je ulaz u Narodni muzej u Beogradu besplatan svake nedelje od 10 do 18 časova. Naposletku, igrom uloga učenici mogu objasniti šta bi posetili kada bi se jedne nedelje našli u nekom italijanskom gradu i gde bi odveli druga iz Italije koji im je došao u posetu. Isto tako, ukoliko govorimo o gestikulaciji, možemo preko videa ili sličica pokazati prvo neke tipično italijanske ili tipično srpske elemente neverbalnog govora, potom pronaći određene gestove koji se podudaraju u obema kulturama i na kraju zajedno reagovati na iste unapred pripremljene iskaze kao pripadnik jedne, odnosno druge kulture.

Na primeru italijanskih dijalekata i Bajramovih savoirs ponudićemo moguć razvoj svesti učenika od učionice do konteksta ciljne kulture. Ukoliko se na času govori o Ujedinjenju Italije i stvaranju italijanskog standardnog jezika, trebalo bi spomenuti i prisustvo dijalekata u svakodnevnici Italijana danas. Učenik će na početku usvojiti znanje o samom postojanju dijalekata (savoir), potom će razviti svoj stav o tome što u zvaničnoj komu- 
nikaciji na primer italijansko dete koristi standardni jezik, a u familijarnom kontekstu dijalekat, poredeći taj fenomen sa svojim dijalektom, manjinskom jezikom ili dijalektom nekog prijatelja (savoir être / comprendre). $\mathrm{Na}$ taj način će učenik postati otvoren i zainteresovan da nauči i poneku reč ili pozdrav na dijalektu svog sadašnjeg ili budućeg prijatelja iz Italije (savoir apprendre / faire), a ukoliko bude boravio u kući tog prijatelja u krajnjoj istanci imaće prilike da realnost sagledava iz sijaseta drugačijih jezičko-kulturoloških aspekata (savoir s'engager).

U Prilogu predlažemo nekoliko primera zadataka za proveru stečene interkulturne kompetencije na osnovnom, srednjem i naprednom nivou za italijanski kao strani jezik u osnovnim školama (u tabelama I, II i III; iskazi preuzeti iz Pravilnik, 2017).

\section{Zaključak}

Značaj razvijene interkulturne kompetencije ogleda se ponajviše u prevazilaženju etnocentričnih stavova i umnom otvaranju za druge kulture. Ona ne podrazumeva samo multikulturnu toleranciju, već buđenje zainteresovanosti za drugačije kulturne modele. Tako osmišljeno obrazovanje pomaže bolje integrisanje u društvu i plasman na tržište rada, kao i razvoj svesti o sopstvenoj kulturi i mogućnost posmatranja situacija iz različitih kulturoloških perspektiva. Učenje stranih jezika ne podrazumeva samo usvajanje jezičkog koda ciljne kulture, već i otvoren stav prema raznovrsnosti i drugačijim obrascima ponašanja i sistemima vrednosti, kako bi se u krajnjoj istanci razvila kritička kulturna svest. Naravno, nemoguće je razviti sve komponente interkulturne kompetencije unutar učionice $u$ ranom učenju jezika tokom osnovnog obrazovanja, ali je važno započeti proces razvoja svesti u tom smeru skretanjem pažnje na kulturološke fenomene. Kao što je već napomenuto, nije jednostavno oceniti nivo interkulturne kompetencije, ali to nikako ne umanjuje njen značaj i mesto u obradi nastavnih sadržaja. U ovom radu smo ponudili moguću primenu Standarda u nastavnoj praksi na osnovu modela i tema koje smo analizirali, kao i zadatke inspirisane kulturnim sadržajima kako bismo podržali njihovo korišćenje u cilju razvijanja obrazovnih potencijala učenika osnovnih škola na časovima stranih jezika. Time smo dokazali veliku upotrebnu vrednost Standarda kao „dobrog sluge“ nastavnicima, učenicima i ostalim akterima u uspešnom i kvalitetnom obrazovnom procesu. 


\section{LITERATURA}

Andrijević, M. (2016). Primena autentičnih materijala u nastavi L2 za sticanje $i$ razvoj interkulturne kompetencije (doktorska disertacija). Filološki fakultet, Univerzitet u Beogradu, Beograd, Republika Srbija.

Beacco, J.-C., Byram, M. \& Cavalli, M. (2016). Guide for the development and implementation of curricula for plurilingual and intercultural education. Strasbourg: Council of Europe.

Buttjes, D. \& Byram M. (1991). Meditating Languages and Cultures: Towards an Intercultural Theory of Foreign Language Education. Clevedon: Multilingual Matters.

Byram, M., Gribkova, B. \& Starkey H. (2002). Developing the Intercultural Dimension in Lanuage Teaching. A Practical Introduction dor Teachers. Strasbourg: Council of Europe, Language Policy Division.

Delors, J. (1996). Learning: The Treasure Within - Report to UNESCO of the International Commission on Education for the Twenty-first Century. Paris: UNESCO.

Dervin, F. (2010). Assessing intercultural competence in Language Learning and Teaching: a critical review of current efforts. [on-line]. Dostupno preko: https://pdfs.semanticscholar.org/c76d/032a17c70eb07a3a7d141ef6934e0 b7590f3.pdf [26.06.2019]

Durbaba, O. (2016). Kultura i nastava stranih jezika. Uvod u interkulturnu primenjenu lingvistiku. Beograd: Filološki fakultet

Durbaba, O., Đurić, Lj., Jovanović, A. et al. (2017). Opšti standardi postignuća za kraj osnovnog obrazovanja za strani jezik. Beograd: Zavod za vrednovanje kvaliteta obrazovanja i vaspitanja.

EPALE (2017). Obrazovanje za interkulturalnu pismenost - pretpostavka celoživotnog učenja. [on-line]. Dostupno preko: https://ec.europa.eu/epale/en/ node/36714 [26.06.2019]

European Commission. (1995). White Paper on Education and Training. Teaching and Learning: Towards the Learning Society. Brussels.

Grupa Most (2007). Vodič za unapređenje interkulturalnog obrazovanja. Beograd: Fond za otvoreno društvo.

Mimica, A. \& Bogdanović, M. (2007). Sociološki rečnik. Beograd: Zavod za udžbenike.

Pravilnik o opštim standardima postignuća za kraj osnovnog obrazovanja za strani jezik (2017). Službeni glasnik RS, br. 78/2017. 
Savjet Evrope (2003). Zajednički evropski okvir za izučavanje, nastavu i ocjenjivanje jezika. Podgorica: Ministarstvo prosvjete i nauke.

Tagliante, K. (2009). Evaluacija i Zajednički evropski okvir. Beograd: Datastatus.

Tomić, Z. (2009). Globalizacija i interkulturna komunikacija. Kultura Polisa, 11/12 487-501. [on-line]. Dostupno preko: http://kpolisa.com/KP11-12/ kp09-VI-1-ZoricaTomic.pdf [26.06.2019]

UNESCO (2003). Sharing a World of Difference: The Earth's Linguistic, Cultural and Biological Diversity. Paris: UNESCO.

\section{Izvori}

Bhabha, H. K. (1994). The location of culture. London: Routledge

Bennett, Milton J. (1993). Towards ethnorelativism: a developmental model of intercultural sensitivity. In Paige, R. M. (Ed.), Education for the intercultural experience (pp. 21-71). Yarmouth, Maine: Intercultural Press

Bennett, Milton J. (2004). Becoming Interculturally Competent. In Wurzel, J. (Ed.), Toward multiculturalism: A reader in multiculturaleducation (pp. 62-77). Newton, MA: Intercultural Resource Corporation.

Kramsch, K. (1993). Context and Culture in Lanuage Teaching. Oxford/New York: Oxford University Press.

\section{PRILOG}

\section{Tabela I}

Osnovni nivo

1.3.1. Poznaje osnovne pojave svakodnevnog života ciljnih kultura (npr. način ishrane, radno vreme, navike, praznici, razonoda).

Nalog: Poveži praznike sa odgovarajućim datumom.

Abbina le feste con le date in cui si festeggiano:

FESTE: 1. Capodanno, 2. Epifania/Befana, 3. Ferragosto, 4. Natale, 5. Festa della Repubblica, 6. Ognissanti

DATE: a) il $1^{\circ}$ novembre, b) il 25 dicembre, c) il 15 agosto, d) il 6 gennaio, e) il 2 giugno, f) il $1^{\circ}$ gennaio 
Tijana B. Gaši

1.3.2. Zna za regije i države u kojima se strani jezik koristi kao većinski.

Nalog: Označi države u kojima je italijanski zvanični jezik.

Seleziona i stati dove italiano viene usato come lingua ufficiale.

Malta, Serbia, Svizzera, Germania, Italia, San Marino, USA, Città del Vaticano, Francia

1.3.3. Poznaje najznačajnije istorijske događaje ciljnih kultura.

Nalog: Dodaj epohe koje nedostaju na vremenskoj liniji od doba Rima do današnjice.

Inserisci i periodi mancanti sulla linea del tempo per arrivare dall'epoca romana ad oggi:

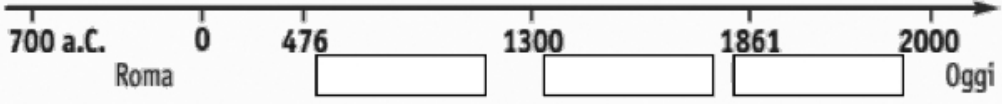

1. Unità d'Italia 2. Medioevo 3. Rinascimento

(vremenska linija preuzeta sa http://italianoperstranieri.loescher.it/che-storia!.n2840)

\section{Tabela II}

Srednji nivo

2.3.1. Razume i opisuje sličnosti i razlike u svakodnevnom životu (npr. način ishrane, radno vreme, navike, praznici, razonoda).

Nalog: Kada se slavi Božić u Italiji, a kada u Srbiji? Objasni kako se praznik obeležava u krugu porodice i koje su sličnosti i razlike između Božića u Srbiji i u Italiji.

Quando si festeggia il Natale in Italia e quando in Serbia? Spiega come si festeggiano in famiglia e quali sono le somiglianze e le differenze tra il Natale in Serbia e in Italia.

2.3.2. Poznaje osnovne elemente u oblasti umeća življenja (način obraćanja i pozdravljanja, tačnost, konvencije i sl.).

Nalog: Napiši tačne pozdravne formule u svakoj rečenici.

Scrivi un esempio per frase con il saluto corretto:

Scusi, Buongiorno, Ciao, Gentile signor Bianchi, Caro Marco, Scusa

Per salutare un amico, puoi dire:

Per salutare il tuo professore d'italiano, puoi dire:

Per scrivere una mail all'amico, puoi cominciare con:

Per scrivere una mail al professore, puoi cominciare con:

Per scusarti con l'amico, puoi dire:

Per scusarti con il professore, puoi dire: 
RAZVOJ INTERKULTURNE KOMPETENCIJE I PRIMENA STANDARDA ...

2.3.8. Predstavlja i ukratko opisuje na ciljnom jeziku nekoliko poznatih ličnosti i pojava iz ciljnih kultura, kao i one za koje pokazuje interesovanje.

Nalog: Izaberi jednu poznatu ličnost iz Italije i objasni svojim drugovima iz škole ko je on/ona, po čemu je poznat/a i zašto si izabrao baš nju/njega.

Scegli un personaggio famoso italiano e spiega ai tuoi compagni chi è, perché è importante e perché hai scelto proprio lui/lei.

\section{Tabela III}

\section{Napredni nivo}

3.3.2. Razume osnovne sličnosti i razlike između svoje i ciljnih kultura u oblasti umeća življenja i prihvata postojanje razlika; primenjuje neke osnovne elemente u oblasti umeća življenja (npr. način obraćanja i pozdravljanja).

Nalog: Marija želi da napiše mejl svom prijatelju Marku Rosiju. Izaberi ispravnu formu od dve ponuđene.

Marija vuole scrivere una mail al suo amico Marco Rossi. Scegli tra le due proposte la forma più adatta:

a) 1. Caro Marco / 2. Egregio signor Rossi,

Ti scrivo per dirti che sono tornato dalle mie vacanze in Montenegro. b) 1. Tu come stai? / 2. Lei come sta? Ho visto dei bellissimi posti e ho fatto il bagno ogni gioro. Ho preso un po' di sole e ho mangiato le ciambelle in spiaggia.

c) 1. Buon proseguimento! / 2. Non vedo l'ora di rivederti!

d) 1. Un abbraccio / 2. Cordiali saluti Marija
a)
b)
c)
d)

3.3.3. Razume i izbegava osnovne oblike neprimerenog/neprikladnog ponašanja $u$ kontekstu ciljnih kultura.

Nalog: Označi sve primere lepog ponašanja.

Seleziona i comportamenti di buona educazione:

1. Non parlare con la bocca piena di cibo.

2. Non mangiare con le posate.

3. Non mettere i gomiti sul tavolo.

4. Non dire "grazie" a chi serve il cibo.

5. Non parlare al cellulare ad alta voce.

3.3.4. Prepoznaje da postoji pristrasnost u tumačenju kulturnih pojava i neguje kritičko mišljenje u njihovom posmatranju i razumevanju. 
Tijana B. Gaši

Nalog: Marko je Italijan koji živi u Palermu, na Siciliji. Marija je Srpkinja koja živi u Novom Sadu. Kada su se upoznali, Marko je rekao da leti ide na more svakog vikenda i nije mu bilo jasno zašto Marija posećuje more jednom godišnje. Objasni Marku kako se provode vikendi i odmori u Srbiji poredeći sa situacijom u Italiji.

Marco è un ragazzo italiano che vive a Palermo, in Sicilia. Marija è una ragazza serba che vive a Novi Sad. Quando si sono conosciuti, Marco ha detto che d'estate va al mare ogni weekend e non capiva perché Marija ci va solo una volta all'anno. Spiega a Marco il perché e motiva la tua risposta spiegando come si trascorrono i weekend e le vacanze in Serbia e come in Italia.

\title{
Tijana B. Gaši
}

\section{LO SVILUPPO DELLA COMPETENZA INTERCULTURALE E L'APPLICAZIONE DEGLI STANDARD PER LA FINE DELLA FORMAZIONE PRIMARIA: LINEE GUIDA PER L'INSEGNAMENTO DELL'ITALIANO COME LINGUA STRANIERA}

\begin{abstract}
Sommario
Nel sistema educativo della Repubblica di Serbia la competenza interculturale è una delle competenze chiave che va sviluppata durante le lezioni di lingue straniere entro la fine del ciclo d'istruzione elementare. Lo sviluppo della consapevolezza interculturale nell'individuo è importante per una sua migliore integrazione nella società di oggi. Tuttavia, l'approccio interculturale è ancora una novità nel percorso formativo e non di rado i contenuti culturali non vengono elaborati nell'anno scolastico a causa del numero ridotto di lezioni di lingua straniera o per via dei problemi di valutazione delle competenze interculturali. Gli standard, d'altra parte, vengono spesso percepiti dagli insegnanti come una pressione aggiuntiva o come una limitazione alla creatività nell'insegnamento. Pertanto, lo scopo di questo lavoro è di sottolineare l'importanza degli elementi interculturali nell'istruzione e di facilitarne l'applicazione dei metodi durante le lezioni di lingua straniera. Il lavoro tratta dello sviluppo dell'approccio interculturale nella glottodidattica e del suo ruolo negli standard. Contiene inoltre suggerimenti e attività per il potenziale utilizzo creativo e pratico degli standard durante le lezioni di italiano come seconda lingua straniera nelle scuole primarie serbe al fine di aiutare gli insegnanti nella selezione dei compiti per lo sviluppo della consapevolezza interculturale negli studenti.
\end{abstract}

Parole chiave: intercultura, cultura, lingue straniere, glottodidattica, competenza interculturale, standard 